Article

\title{
Electrostatic immobilization of phosphomolybdic acid on imidazolium-based mesoporous organosilicas for catalytic olefin epoxidation
}

\author{
Jing Wang a,b, Yongcun Zou c, Yu Sun ${ }^{\mathrm{b}}$, Maximilian Hemgesberg b, Dirk Schaffner ${ }^{\mathrm{b}}$, Hongcheng Gao a, \\ Xiaojing Song a, Wenxiang Zhang ${ }^{a}$, Mingjun Jia ${ }^{a}, *$, Werner R. Thiel ${ }^{b, \#}$ \\ a State Key Laboratory of Theoretical and Computational Chemistry, College of Chemistry, Jilin University, Changchun 130021, Jilin, China \\ ${ }^{\mathrm{b}}$ Faculty of Chemisity, Technical University of Kaiserslautern, Erwin-Schroedinger-Str., Building 54, Kaiserslautern 67663, Germany \\ ' State Key Laboratory of Inorganic Synthesis and Preparative Chemistry, College of Chemistry, Jilin University, Changchun 130012, Jilin, China
}

\section{A R T I C L E I N F O}

Article history:

Received 14 November 2013

Accepted 2 January 2014

Published 20 April 2014

\section{Keywords:}

Polyoxometalate

Mesoporous organosilica

Imidazolium cation

Electrostatic interaction

Epoxidation

Heterogeneous catalysis

\begin{abstract}
A B S T R A C T
Polyoxometalate-based heterogeneous materials were prepared by the immobilization of 12-phosphomolybdic acid (PMA) on periodic mesoporous organosilicas containing embedded imidazolium cations (PMO-ILs). The resulting hybrid materials (PMA@PMO-ILs) were characterized by $\mathrm{N}_{2}$ adsorption-desorption, powder X-ray diffraction, atomic adsorption spectroscopy, thermogravimetric and differential thermal analyses, Fourier transform infrared spectroscopy, ultraviolet-visible diffuse reflectance spectroscopy, and solid-state cross-polarization magic angle spinning nuclear magnetic resonance. PMA was electrostatically immobilized on the surface and in the channels of PMO-ILs. The PMO-IL support and PMA structures were retained during the preparation processes. The catalytic properties of the PMA@PMO-ILs were evaluated for the liquid-phase epoxidation of cyclooctene. PMA@PMO-ILs were catalytically active, with nearly 100\% selectivity to cyclooctene epoxide using tert-butyl hydroperoxide as the oxidant. The catalysts could be reused four times without obvious loss of activity or selectivity under identical reaction conditions. Imidazolium cations in the PMO-IL framework improved the stability and recyclability of the PMA immobilized catalysts.
\end{abstract}

(C) 2014, Dalian Institute of Chemical Physics, Chinese Academy of Sciences. Published by Elsevier B.V. All rights reserved.

\section{Introduction}

The catalytic oxidation (or epoxidation) of olefins is an important reaction in chemical industry [1-4]. Polyoxometalates (POMs) are a class of early-transition-metal oxides with controllable redox properties and have shown attractive catalytic performance in the selective oxidation of olefins [5-10]. Much recent effort has been focused on achieving the heterogenization of homogeneous POM catalysts in order to overcome their drawbacks, separation and recycling problems. Different preparation strategies have been developed to obtain heterogeneous POM-based catalysts. These include immobilizing POMs on porous support surfaces [11-18], incorporating POMs in silica or metal oxide matrices via sol-gel techniques [19-23], encapsulating POMs within nanocages of metal-organic frameworks [24-26], and self-assembling POMs with organic compounds to form supramolecular structures [27].

To obtain highly efficient and stable POM-based heteroge-

\footnotetext{
* Corresponding author. Tel: +86-431-85155390; Fax: +86-431-88499140; E-mail: jiamj@jlu.edu.cn

\# Corresponding author. Tel: +49-631-2052752; Fax: +49-631-2054676; E-mail: thiel@chemie.uni-kl.de

This work was supported by the China Scholarship Council and the National Natural Science Foundation of China (21173100).

DOI: 10.1016/S1872-2067(14)60025-5 | http://www.sciencedirect.com/science/journal/18722067 | Chin. J. Catal., Vol. 35, No. 4, April 2014
} 
neous catalysts, an appropriate interaction between POM and the support (or host) is usually necessary. This may include covalent bonds, electrostatic binding, hydrogen bonds, and/or other interactions. The support should possess a sufficiently high surface area, a large pore size, and a suitable surface polarity, as these parameters influence the distribution and accessibility of catalytically active species. Optimizing preparation methods and conditions has led to significant recent progress on preparing heterogeneous POM-based catalysts. Kasai et al. [11] immobilized polyoxometalate anions of $\left[\gamma-1,2-\mathrm{H}_{2} \mathrm{SiV}_{2} \mathrm{~W}_{10} \mathrm{O}_{40}\right]^{4-}$ on the surface of dihydroimidazolium-cation modified $\mathrm{SiO}_{2}$ by anion exchange, and this catalyst heterogeneously oxidized a broad range of olefins and sulfides. Armatas et al. [19] immobilized 12-phosphomolybdic acid anions in a zirconia matrix by sol-gel copolymerization, and this catalyst exhibited high activity and stability in the oxidation of alkenes. Qi et al. [20] immobilized surfactant-encapsulated polyoxometalate complexes in a silica matrix through a sol-gel process. The resulting supramolecular hybrid catalyst was highly active and stable for the selective oxidation of various organic substrates. Zhao et al. [28] immobilized ionic 12-tungstophosphoric acid-(dihydro)imidazolium complexes in mesoporous SBA-15 using a one-pot procedure. The resulting hybrid exhibited high catalytic efficiency and reusability in selective alcohol oxidations with $\mathrm{H}_{2} \mathrm{O}_{2}$ as the oxygen source. We recently synthesized supramolecular assemblies based on octamolybdate and imidazole by a one-step hydrothermal method. The resulting hybrids exhibited excellent catalytic activity and stability in the epoxidation of olefins with tert-butyl hydroperoxide $(t \mathrm{BuOOH})$ as the oxidant [27]. Designing and preparing efficient POM-based heterogeneous catalysts for selective oxidation and epoxidation remain an attractive research area.

Periodic mesoporous organosilica containing embedded imidazolium cations (PMO-IL) was recently synthesized by controlling the hydrolysis and co-condensation of a disilylated imidazolium based ionic liquid (IL) [29-34]. Such materials combine the advantages of the mesoporous material and IL. The PMO-IL possessed a high alkyl imidazolium loading, high specific surface area, large uniform pore size, and outstanding hydrothermal stability and ion exchange properties. Various recent studies showed that PMO-IL could serve as a host for dispersing and stabilizing noble metal species/particles. The resulting materials were highly active and stable heterogeneous hybrid catalysts for coupling reactions [29,30], aerobic oxidation of alcohols [31,32], and olefin hydrogenation [33].

In the present study, PMO-ILs containing different imidazolium cation contents were used as supports for the electrostatic immobilization of 12-phosphomolybdic acid (PMA). The resulting materials (PMA@PMO-ILs) were characterized, and their catalytic performance was investigated in the liquid-phase epoxidation of cyclooctene with $t \mathrm{BuOOH}$ as the oxidant.

\section{Experimental}

\subsection{Materials}

Sodium hydride $(\mathrm{NaH})$, imidazole, 3-iodopropyltrimethoxysilane, PEG-PPG-PEG (P123), tetraethoxysilane (TEOS), 12phosphomolybdic acid $\left(\mathrm{H}_{3} \mathrm{PMo}_{12} \mathrm{O}_{40} \cdot 28 \mathrm{H}_{2} \mathrm{O}\right)$, cis-cyclooctene, $n$-dodecane, tert-butyl hydroperoxide $(t \mathrm{BuOOH})$, and all solvents (dried by standard procedures) were purchased from Sigma-Aldrich. All manipulations involving air-sensitive materials were performed using the Schlenk line technique under $\mathrm{N}_{2}$ atmosphere.

\subsection{Preparation}

\subsubsection{Preparation of PMO-ILs ( $\boldsymbol{a}$ and $\boldsymbol{b}$ )}

$N$-(3-Propyltrimethoxysilane)imidazole and 1,3-di(3propyltrimethoxysilane)imidazolium iodide (1) were synthesized according to literature procedures [33,34]. PMO-ILs with various imidazolium cation contents were prepared according to Wang et al. [33]. Typically, P123 (2 g) was dissolved in 2 mol/L $\mathrm{HCl}(60 \mathrm{ml}) . \mathrm{H}_{2} \mathrm{O}(15 \mathrm{ml})$ was added, and the solution was stirred at room temperature for $2 \mathrm{~h}$. A mixture of $\mathbf{1}$ and TEOS/ethanol was added dropwise to the above solution, leading to a composition of $\mathrm{SiO}_{2} / \mathbf{1} / \mathrm{P} 123 / \mathrm{HCl} /$ ethanol $/ \mathrm{H}_{2} \mathrm{O}$ molar ratio of $(1.0-x): x: 0.017: 6.0: 4.0: 208(x=0.10$ for $\mathbf{a}, 0.15$ for b). The mixture was stirred at room temperature for $3 \mathrm{~h}$, then heated to $38^{\circ} \mathrm{C}$ for $24 \mathrm{~h}$ and subsequently aged at $100{ }^{\circ} \mathrm{C}$ for $72 \mathrm{~h}$. The obtained solid material was filtered and washed with deionized water, and the template was extracted with ethanol in a Soxhlet apparatus for $24 \mathrm{~h}$. The resulting solids (a and b) were dried under vacuum at $50{ }^{\circ} \mathrm{C}$. Anal. found for $\mathbf{a}$ (\%): C 13.52; H 3.31; N 3.03. Anal. found for b (\%): C 17.23; $\mathrm{H}$ 3.54; N 4.44 .

\subsubsection{Preparation of PMA@PMO-ILs (2a and $\mathbf{2 b}$ )}

PMO-ILs a or b (1 g) was vigorously stirred with $\mathrm{H}_{3} \mathrm{PMo}_{12} \mathrm{O}_{40} \cdot 28 \mathrm{H}_{2} \mathrm{O}(0.4 \mathrm{~g})$ in methanol $(20 \mathrm{ml})$ at $30{ }^{\circ} \mathrm{C}$ for 24 h. The solid was filtered off, washed with excess methanol, and extracted with methanol in a Soxhlet apparatus for $12 \mathrm{~h}$. The obtained solids (2a or $\mathbf{2 b}$ ) were dried under vacuum at $50{ }^{\circ} \mathrm{C}$ (Scheme 1). The PMA loading was calculated by atomic adsorption spectroscopy (AAS), as shown in Table 1.

PMA-functionalized SBA-15 (2c) was also prepared following the above procedure, using mesoporous SBA-15 in place of PMO-IL [15]. The PMA loading calculated by AAS in $2 \mathbf{c}$ was 0.04 $\mathrm{mmol} / \mathrm{g}$.

\subsection{Characterization}

Elemental analyses for $\mathrm{C}, \mathrm{H}$, and $\mathrm{N}$ were performed on a Carlo Erba instrument (model EA 1108). AAS was performed

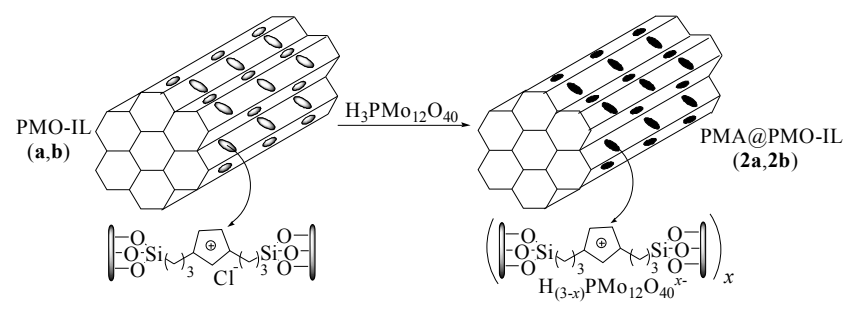

Scheme 1. Preparation of $\mathbf{2 a}$ and $\mathbf{2 b}$. 
on a Perkin Elmer Analyst 300. $\mathrm{N}_{2}$ adsorption-desorption isotherms were measured at $-196{ }^{\circ} \mathrm{C}$ using a Quantachrome Autosorb 1 sorption analyzer. All samples were degassed at $130{ }^{\circ} \mathrm{C}$ for $12 \mathrm{~h}$ before measurement. Surface areas were calculated using the BET method on the adsorption data at $p / p_{0}=$ $0.05-0.2$. Total pore volumes were derived at $p / p_{0}=0.95$, assuming full surface saturation with $\mathrm{N}_{2}$. Pore size distributions were estimated from the adsorption branch of isotherms using the BJH model. Powder X-ray diffraction (XRD) patterns were recorded on a Shimadzu XRD-6000 diffractometer $(40 \mathrm{kV}, 30$ $\mathrm{mA}$ ), using Ni-filtered $\mathrm{Cu} K_{\alpha}$ radiation. Thermogravimetric and differential thermal analyses (TG-DTA) were carried out using a SETARAM Setsys 16/MS instrument, with an air flow and heating rate of $5{ }^{\circ} \mathrm{C} / \mathrm{min}$, from room temperature to $800{ }^{\circ} \mathrm{C}$. Fourier transform infrared (FT-IR) spectra were recorded using a Nicolet AVATAR 370 DTGS spectrometer in the range 4000-500 $\mathrm{cm}^{-1}$. Diffuse reflectance ultraviolet-visible (UV-Vis) spectra of solid samples were recorded on a Shimadzu 3600 spectrometer in the range $200-800 \mathrm{~nm}$. Liquid phase NMR spectra were recorded with Bruker Avance 400 or 600 spectrometers. Solid-state ${ }^{13} \mathrm{C},{ }^{29} \mathrm{Si}$, and ${ }^{31} \mathrm{P}$ cross-polarization-magic angle spinning (CP-MAS) NMR spectra were recorded on a Bruker DSX Avance spectrometer at resonance frequencies of 100.6, 79.5, and $162.0 \mathrm{MHz}$, respectively.

\subsection{Catalytic reactions}

The catalytic epoxidation of cyclooctene was carried as follows. Cyclooctene ( $5.0 \mathrm{mmol}$ ), $5.0 \mathrm{mmol}$ of $n$-dodecane (internal standard), $100 \mathrm{mg}$ of solid catalyst, and $10 \mathrm{ml}$ of $\mathrm{CHCl}_{3}$ were added to a $25 \mathrm{ml}$ flask. The suspension was stirred at a specific
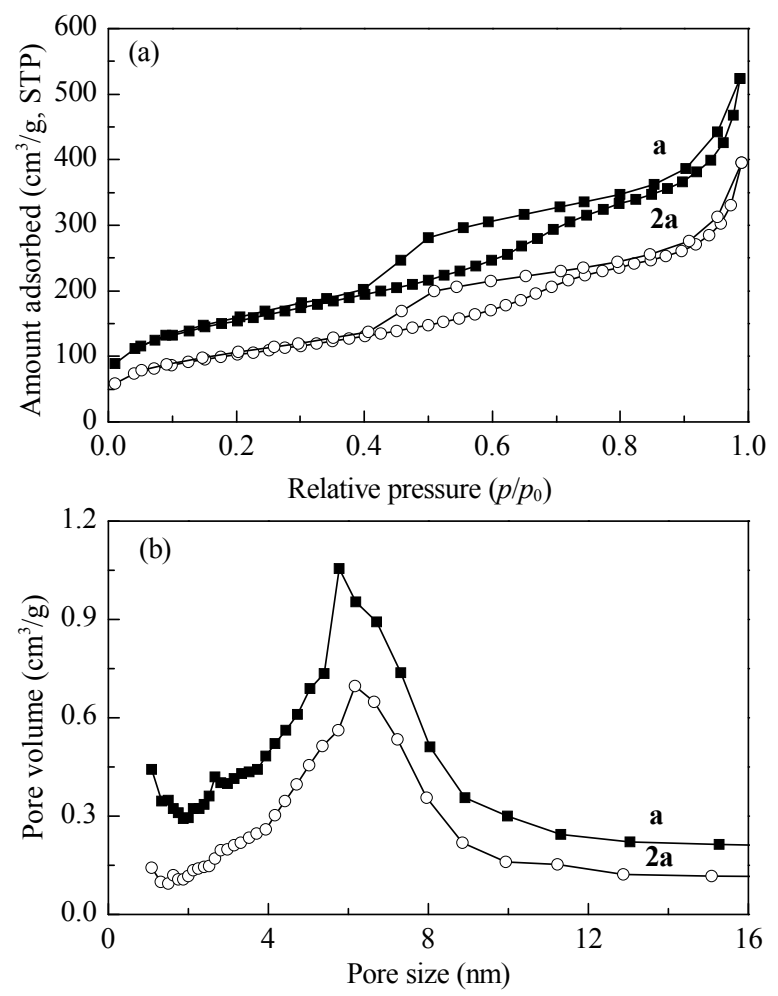

temperature, and then $1.0 \mathrm{ml}$ of $5.5 \mathrm{~mol} / \mathrm{L} t \mathrm{BuOOH}$ in decane was added to start the reaction. After conducting the reaction, the catalyst was filtered off, washed with $\mathrm{CHCl}_{3}$, dried under vacuum at $50{ }^{\circ} \mathrm{C}$, and reused directly without further purification. The course of the reaction was monitored by quantitative gas chromatography. The catalytic activity for the epoxidation of cyclooctene was evaluated by the conversion of cyclooctene to cyclooctene epoxide.

\section{Results and discussion}

\subsection{Characterization of catalysts}

\subsection{1. $\quad N_{2}$ adsorption-desorption}

The textural properties of $\mathbf{a}, \mathbf{b}, \mathbf{2 a}$, and $\mathbf{2} \mathbf{b}$ were evaluated by $\mathrm{N}_{2}$ adsorption-desorption experiments. These samples exhibit type IV isotherms according to the IUPAC classification, which is characteristic of mesoporous materials (Fig. 1). The appearance of $\mathrm{H} 2$ hysteresis loops with adsorption branches at a relative pressure of 0.8 and desorption branches at a relative pressure of 0.4 implies "ink-bottle" type pores [35]. Sample b possesses a smaller surface area and pore volume than a, which is attributed to a greater content of bulky imidazolium cations in the framework, and thus more strain in the mesostructure [32,33]. Samples $\mathbf{2 a}$ and $\mathbf{2 b}$ exhibit smaller surface areas, pore sizes, and pore volumes than $\mathbf{a}$ and $\mathbf{b}$ because of the incorporation of PMA into the PMO-ILs (Table 1) [29,36].

\subsection{2. $X R D$}

The XRD patterns of unsupported PMA, the PMO-IL supports $\mathbf{a}$ and $\mathbf{b}$, and the PMA-based catalysts $\mathbf{2} \mathbf{a}$ and $\mathbf{2} \mathbf{b}$ are
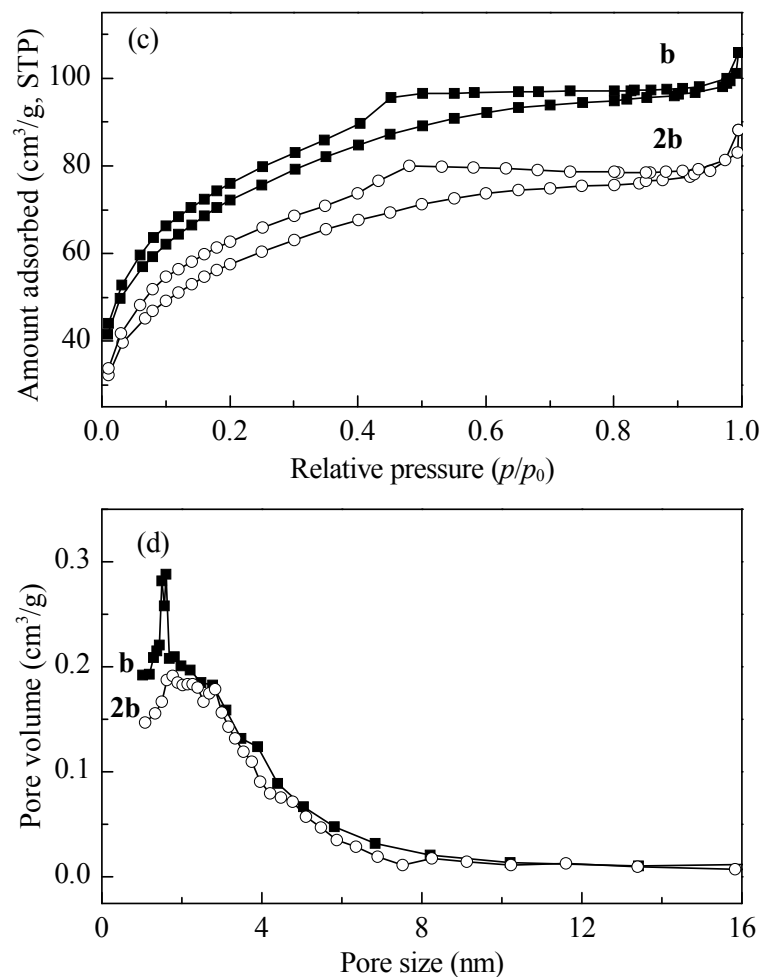

Fig. 1. $N_{2}$ adsorption-desorption isotherms $(a, c)$ and pore size distribution curves (b,d) of $\mathbf{a}, \mathbf{b}, \mathbf{2 a}, \mathbf{a n d} \mathbf{2} \mathbf{b}$. 
Table 1

Physical properties of $\mathbf{a}, \mathbf{b}, \mathbf{2 a}$, and $\mathbf{2 b}$.

\begin{tabular}{lccccc}
\hline Sample & $\begin{array}{c}\text { BET surface } \\
\text { area }\left(\mathrm{m}^{2} / \mathrm{g}\right)\end{array}$ & $\begin{array}{c}\text { Pore volume } \\
\left(\mathrm{cm}^{3} / \mathrm{g}\right)\end{array}$ & $\begin{array}{c}\text { Pore diameter } \\
(\mathrm{nm})\end{array}$ & $\begin{array}{c}\text { Content of 1a } \\
(\mathrm{mmol} / \mathrm{g})\end{array}$ & $\begin{array}{c}\text { Content of PMA } \\
\left(\mathrm{mmol}^{\mathrm{b}} / \mathrm{g}\right)\end{array}$ \\
\hline $\mathbf{a}$ & 555 & 0.68 & 5.0 & 1.0 & - \\
$\mathbf{2 a}$ & 370 & 0.48 & 4.9 & 1.0 & 0.10 \\
$\mathbf{b}$ & 251 & 0.15 & 3.0 & 1.5 & - \\
$\mathbf{2 b}$ & 200 & 0.13 & 2.9 & 1.5 & 0.07 \\
\hline
\end{tabular}

a Calculated from the nitrogen content indicated by elemental analysis.

${ }^{\mathrm{b}}$ Calculated from AAS analysis.

shown in Fig. 2. Unsupported PMA exhibits characteristic XRD peaks at $2 \theta=18^{\circ}-30^{\circ}[37,38]$. All hybrid materials exhibit negligible reflections at low-angle, suggesting the absence of long-range ordering. In the wide-angle region, $\mathbf{a}, \mathbf{b}, \mathbf{2 a}$, and $\mathbf{2 b}$ exhibit only one very broad peak centered at $22^{\circ}$, which is a characteristic of amorphous materials [35]. The absence of characteristic peaks of PMA in the XRD patterns of $\mathbf{2 a}$ and $\mathbf{2 b}$ suggests that PMA units are well-dispersed on the surface and in the channels of the PMO-IL supports $[37,38]$.

\subsubsection{TG-DTA}

TG-DTA was carried out to estimate the thermal stability of 2a (Fig. 3). A small weight loss below $100{ }^{\circ} \mathrm{C}$ is attributed to the desorption of adsorbed water and ethanol from pore channels. The obvious weight loss at $300-500{ }^{\circ} \mathrm{C}$ is due to the thermal dissociation of imidazolium moieties and PMA. This indicates that $\mathbf{2 a}$ is thermally stable up to at least $300^{\circ} \mathrm{C}[14,33,39]$.

\subsubsection{FT-IR}

FT-IR spectra of $\mathbf{a}, \mathbf{2 a}, \mathbf{2 b}$, and pure PMA are shown in Fig. 4. All hybrid materials exhibit absorptions at 1067 and $925 \mathrm{~cm}^{-1}$, which correspond to the stretching vibration of $\mathrm{Si}-\mathrm{O}-\mathrm{Si}$. Absorptions at 1456,1561 , and $1625 \mathrm{~cm}^{-1}$ correspond to $\mathrm{C}-\mathrm{H}$ bending vibrations, or $\mathrm{C}=\mathrm{C}$ and $\mathrm{C}=\mathrm{N}$ stretching vibrations of the imidazolium ring, respectively [29,33]. In the spectrum of PMA, bands occur at $1064\left(\mathrm{P}-\mathrm{O}_{\mathrm{a}}\right.$ stretching mode), $959\left(\mathrm{Mo}=\mathrm{O}_{\mathrm{t}}\right.$ terminal bonds), 864 (Mo- $\mathrm{O}_{\mathrm{b}}-\mathrm{Mo}$ inter-bridge bonds), and 784 (Mo-Oc-Mo intra-bridge bonds) $\mathrm{cm}^{-1}$. For $\mathbf{2 a}$ and $\mathbf{2 b}$, a signifi-

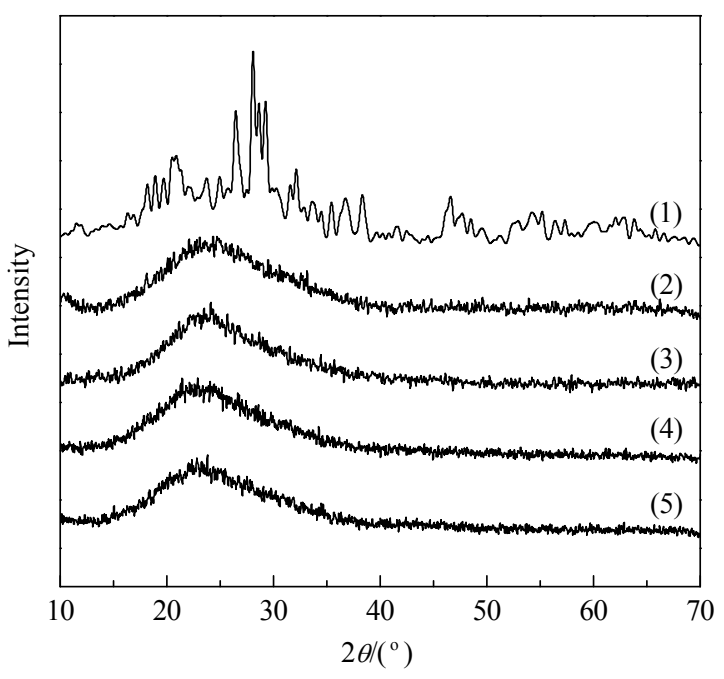

Fig. 2. XRD patterns of PMA (1), $\mathbf{2 b}(2), \mathbf{2 a}(3), \mathbf{b}(4)$, and a (5) samples.

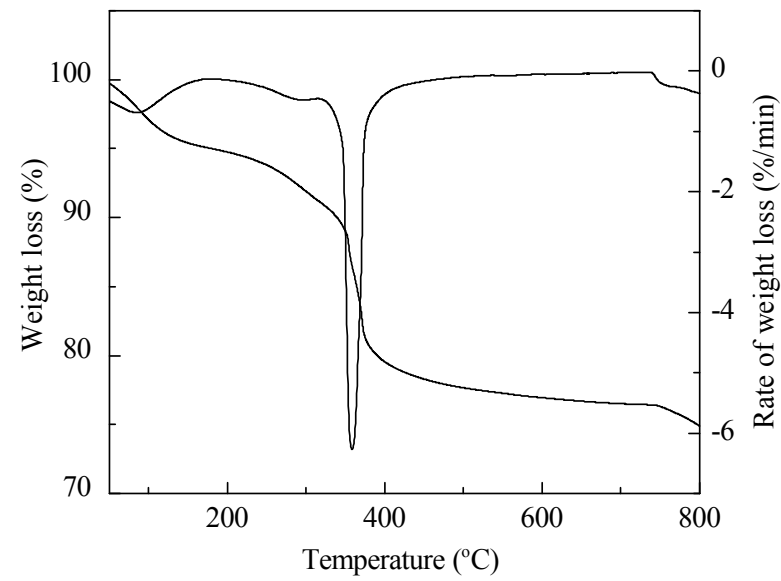

Fig. 3. TG-DTA curves of $\mathbf{2 a}$

cant shift in the Mo- $\mathrm{O}_{\mathrm{b}}-\mathrm{Mo}\left(882 \mathrm{~cm}^{-1}\right)$ and Mo- $\mathrm{O}_{\mathrm{c}}-\mathrm{Mo}(810$ $\mathrm{cm}^{-1}$ ) bands is observed, indicating the interaction between heteropoly acid anions and the PMO-IL support [15,19,40].

\subsection{5. $U V$-Vis}

UV-Vis spectra of PMA, a, b, 2a, and $\mathbf{2 b}$ are shown in Fig. 5. Neat PMA exhibits characteristic absorptions at $\sim 217$ and $\sim 313 \mathrm{~nm}$, which arise from charge transition from $\mathrm{O}^{2-}$ to $\mathrm{Mo}^{6+}$ in $\mathrm{Mo}=\mathrm{O}$ and Mo-O-Mo bonds, respectively. For $\mathbf{2 a}$ and $\mathbf{2 b}$, these absorption peaks exhibit a small shift, indicating interactions between PMA anions and imidazolium cations in the mesoporous materials [12].

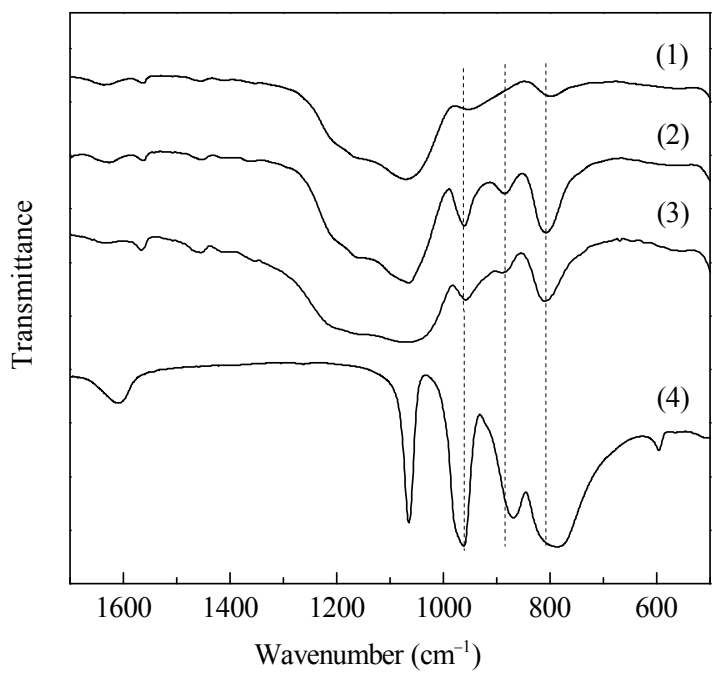

Fig. 4. FT-IR spectra of a (1), 2a (2), 2b (3), and PMA (4). 


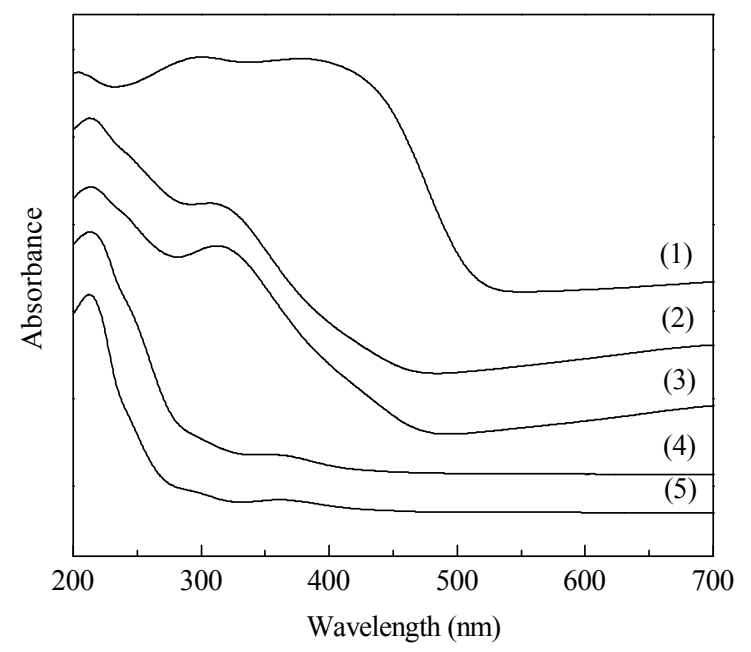

Fig. 5. UV-Vis spectra of PMA (1), 2b (2), 2a (3), b (4), and a (5).

\subsection{6. $N M R$}

Solid-state ${ }^{13} \mathrm{C}$ CP-MAS NMR was used to determine the nature of imidazolium compound incorporation in $\mathbf{2} \mathbf{a}$ and $\mathbf{2 b}$ (Fig. 6). $\mathbf{2 a}$ and $\mathbf{2 b}$ exhibit resonances typical of imidazolium rings (NCHN $\delta=136.5$, CHCH $\delta=122.1$ ) and propylene chains $\left(\mathrm{SiCH}_{2}\right.$ $\delta=5.9, \mathrm{CH}_{2} \mathrm{CH}_{2} \mathrm{CH}_{2} \delta=24.2, \mathrm{CH}_{2} \mathrm{~N} \delta=51.8$ ). These chemical shifts are comparable with those in the ${ }^{13} \mathrm{C}$ NMR spectrum of the parent imidazolium IL. The absence of any further carbon signal indicates the preservation of the IL bridging structure during synthesis, extraction and PMA immobilization $[29,32,33]$.

${ }^{29}$ Si CP-MAS NMR spectra provide direct evidence for the covalent bonding of silica species in the mesoporous materials (Fig. 7). The spectra of $\mathbf{2 a}$ and $\mathbf{2} \mathbf{b}$ exhibit resonances at $\delta=$ $-110,-100$, and -92 , which correspond to the framework silica sites $\mathrm{Q}^{4}$ (silicon atoms without hydroxyl groups $\left.\mathrm{Si}(\mathrm{OSi})_{4}\right), \mathrm{Q}^{3}$ (isolated hydroxyl group $\mathrm{Si}(\mathrm{OSi})_{3}(\mathrm{OH})$ ), and $\mathrm{Q}^{2}$ (germinal silandiols $\left.\mathrm{Si}(\mathrm{OSi})_{2}(\mathrm{OH})_{2}\right)$, respectively. Signals at $\delta=-66$ and -58 are due to $\mathrm{T}^{3}\left(\mathrm{R}-\mathrm{Si}(\mathrm{OSi})_{3}\right)$ and $\mathrm{T}^{2}\left(\mathrm{R}-\mathrm{Si}(\mathrm{OH})(\mathrm{OSi})_{2}\right)$ sites, respectively. The presence of $\mathrm{T}^{3}$ and $\mathrm{T}^{2}$ functionalities indicates that sufficient cross-linking occurs between the silylated IL and

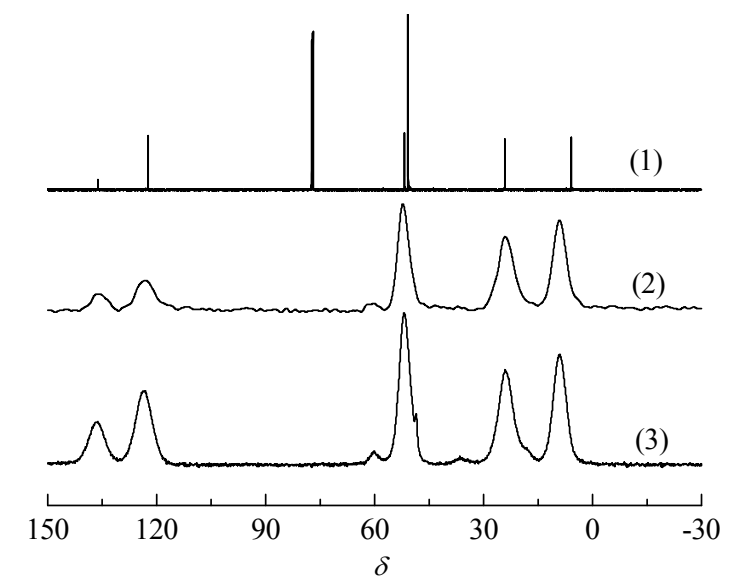

Fig. 6. ${ }^{13} \mathrm{C}$ NMR spectrum of $\mathbf{1}(1)$ and solid-state ${ }^{13} \mathrm{C}$ CP-MAS NMR spectra of $\mathbf{2 a}(2)$ and $\mathbf{2 b}$ (3).

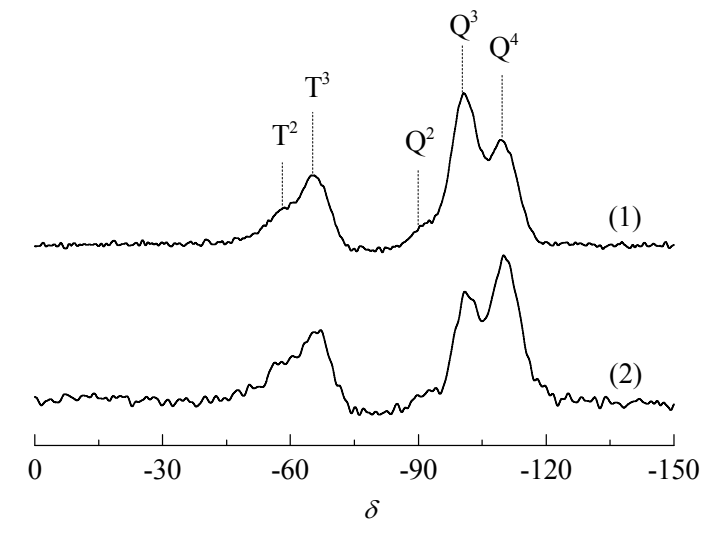

Fig. 7. Solid-state ${ }^{29}$ Si CP-MAS NMR spectra of $\mathbf{2 a}(1)$ and $\mathbf{2 b}$ (2).

TEOS during condensation. This results in a strong linkage (predominantly three $\mathrm{Si}-\mathrm{O}-\mathrm{Si}$ covalent bonds) between the bridging imidazolium cations and silica matrix [32].

Solid-state ${ }^{31 P}$ CP-MAS NMR spectra of PMA and 2a are shown in Fig. 8. The spectrum of 2 a exhibits a resonance peak of structural $\mathrm{P}$ at around $\delta=-3.2$, which is comparable with the $\mathrm{P}$ resonance in pure PMA. ${ }^{31} \mathrm{P}$ NMR resonances are sensitive to the $\mathrm{P}$ atom coordination environment. The unchanged chemical shift of structural P in 2a suggests that the PMA structure is retained during immobilization [20]. The small half-width of the resonance indicates a highly symmetric environment about $\mathrm{P}$ in both free PMA and 2a.

\subsection{Catalytic properties}

The catalytic performance of $\mathbf{2 a}$ and $\mathbf{2} \mathbf{b}$ was investigated in the epoxidation of cyclooctene using $t \mathrm{BuOOH}$ as the oxidant and $\mathrm{CHCl}_{3}$ as the solvent. The catalytic properties of PMA-functionalized SBA-15 (2c) were also investigated under identical reaction conditions. Figure 9 shows that all catalysts are active for the epoxidation of cyclooctene. $\mathbf{2 a}$ and $\mathbf{2} \mathbf{b}$ give $90 \%$ and $72 \%$ yields of cyclooctene epoxide after $12 \mathrm{~h}$ of reaction at $50{ }^{\circ} \mathrm{C}$, respectively. The reference catalyst $2 \mathrm{c}$ is more active, providing a 90\% yield of cyclooctene epoxide after $7 \mathrm{~h}$ of reaction. All three PMA-based catalysts exhibit very high selectivity to cyclooctene epoxide ( $\geq 99 \%$ ), and no detectable side

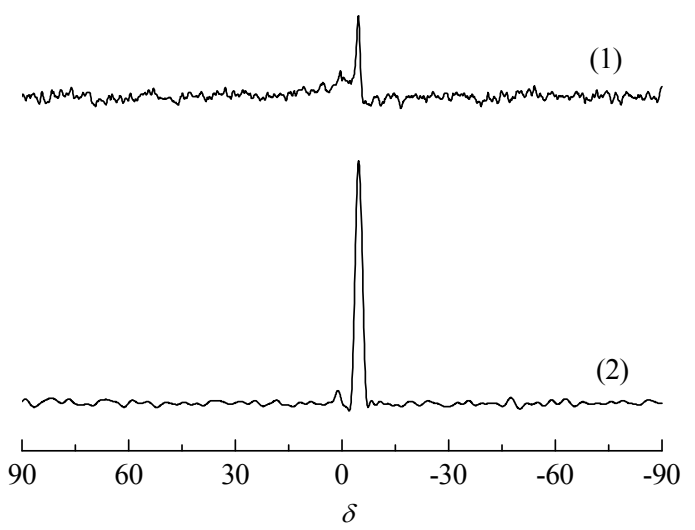

Fig. 8. Solid-state ${ }^{31} \mathrm{P}$ CP-MAS NMR spectra of 2a (1) and PMA (2). 


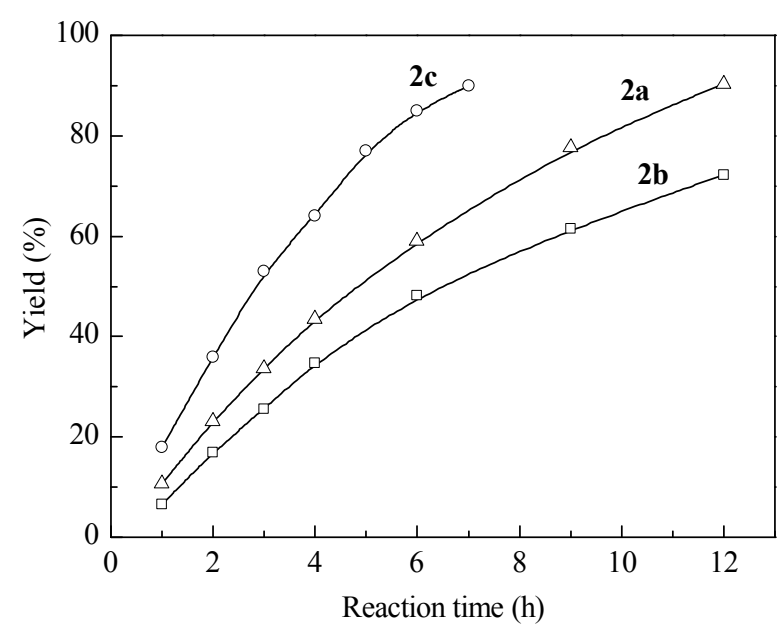

Fig. 9. Kinetic profiles of the epoxidation of cyclooctene over $\mathbf{2 a}, \mathbf{2} \mathbf{b}$, and 2c. Reaction conditions: cis-cyclooctene $5.0 \mathrm{mmol}, n$-dodecane 5.0 mmol (internal standard), $t \mathrm{BuOOH} 5.0 \mathrm{mmol}$, catalyst $100 \mathrm{mg}$, chloroform $10 \mathrm{ml}, 50^{\circ} \mathrm{C}$. All selectivities for the epoxide are $\geq 99 \%$.

products are observed under the test conditions.

The stability of the active species is extremely important in heterogeneous catalysts. Leaching tests were conducted for $\mathbf{2 a}$, 2b, and 2c (Fig. 10). In duplicate reactions, the solid catalysts were separated by hot filtration, and the filtrate was then further stirred. Continued activity at the reaction temperature was monitored. For $\mathbf{2 a}$, cyclooctene is converted at a very low rate in the filtrate, which demonstrates that very little active material leached from the hybrid catalyst, and that the vast majority of catalysis is performed by the heterogeneous catalyst. For $\mathbf{2 b}$, the epoxidation rate after removing the catalyst is marginally higher than that for $\mathbf{2 a}$. For $\mathbf{2 c}$, the yield of cyclooctene epoxide in the filtrate increases from $36 \%$ to $67 \%$ after $5 \mathrm{~h}$, indicating that a significant amount of PMA leaching occurs during the reaction course. Thus, homogeneous catalysis is at least partly responsible for the high activity of $\mathbf{2 c}$.

The recycling behavior of the solid catalysts was investigated using dried catalysts recovered by filtration and washed

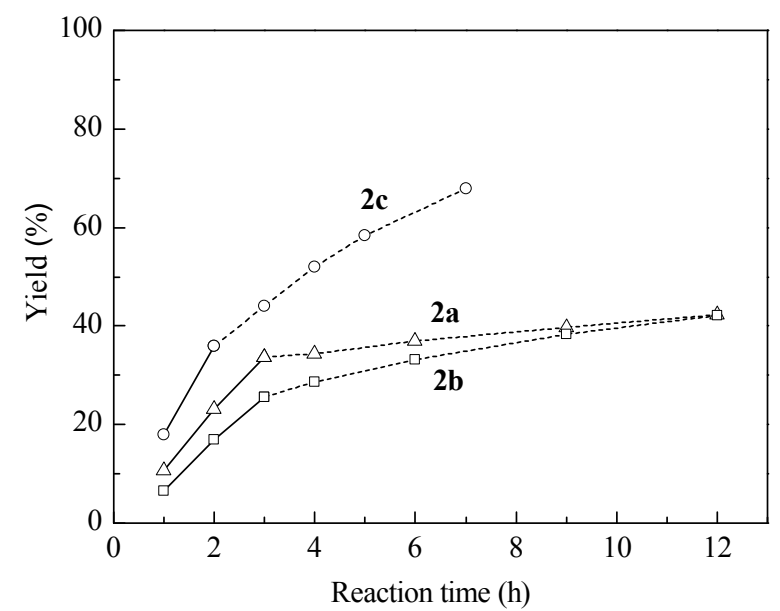

Fig. 10. Leaching experiments of $\mathbf{2 a}, \mathbf{2 b}$, and 2c. Dashed lines indicate cyclooctene conversion after the removal of the catalysts. Reaction conditions are analogous to those in Fig. 9.
Table 2

Recyclability of $\mathbf{2 a}, \mathbf{2 b}$, and $\mathbf{2 c}$ for the epoxidation of cyclooctene with $t \mathrm{BuOOH}$ as the oxidant.

\begin{tabular}{lccccc}
\hline \multirow{2}{*}{ Catalyst } & \multicolumn{5}{c}{ Yield (\%) } \\
\cline { 2 - 6 } & Run 1 & Run 2 & Run 3 & Run 4 & Run 5 \\
\hline 2a & 90 & 89 & 89 & 88 & 88 \\
2b & 72 & 70 & 67 & 67 & 66 \\
2c & 90 & 80 & 72 & 66 & 60 \\
\hline
\end{tabular}

Reaction time: $12 \mathrm{~h}$ for $\mathbf{2 a}$ and $\mathbf{2 b}$, and $7 \mathrm{~h}$ for $\mathbf{2 c}$.

with $\mathrm{CHCl}_{3}$ (Table 2). 2a can be reused at least four times without obvious loss of activity and selectivity under identical reaction conditions. $\mathbf{2 b}$ exhibits a slight decrease after the initial cycle, and conversion of cyclooctene is largely retained after the second cycle, which is because of the loss of trace immobilized PMA. 2c exhibits an obvious decrease in catalytic activity with increasing cycling numbers, suggesting a poor reusability.

The influence of solvent and oxidant on the catalytic properties of 2a was also evaluated (Table 3). Under the tested conditions, the catalytic activity of $\mathbf{2 a}$ changes considerably with different solvents. The yield of cyclooctene epoxide decreases in the order of chloroform $>$ acetonitrile $>$ ethanol $>$ toluene, indicating that the catalytic properties of $\mathbf{2 a}$ are solvent dependent. To estimate the influence of the oxidant, $30 \%$ aqueous $\mathrm{H}_{2} \mathrm{O}_{2}$ was applied in the epoxidation of cyclooctene. As shown in Table 3, 2a exhibits lower activity when using $\mathrm{H}_{2} \mathrm{O}_{2}$ as an oxidant, compared with the $t \mathrm{BuOOH}$-based system. Obvious leaching of the PMA active species is also observed when $\mathrm{H}_{2} \mathrm{O}_{2}$ is used as the oxidant. These results indicate that $t \mathrm{BuOOH}$ is a more suitable oxidant than $\mathrm{H}_{2} \mathrm{O}_{2}$ for the PMA@PMO-IL catalytic system.

Polyoxometalates are reportedly active homogeneous catalysts for the epoxidation of olefins $[7,41]$. Hence, it is reasonable to expect that PMA@PMO-ILs catalysts should exhibit good activity in the epoxidation of cyclooctene. Similar to the homogeneous PMA catalyst, the supported PMA anions in $\mathbf{2 a}$ or $\mathbf{2 b}$ are the major active centers for epoxidation. These could activate the $t \mathrm{BuOOH}$ oxidant to form oxoperoxide intermediates and then facilitate the transfer of oxygen from the oxidant to the olefin $[7,15,42,43]$.

The high stability and reusability of $\mathbf{2 a}$ and $\mathbf{2 b}$ are attributed to imidazolium cations in the PMO-IL support. Considering the ionic nature of the imidazolium group in the PMO-IL, it is believed that the PMO-IL nanostructure acts as an anion exchanger, allowing PMA anions to be immobilized on the PMO-IL through anion exchange [30]. An additional experiment was performed to prove the anion exchange reaction between PMA

Table 3

Epoxidation of cis-cyclooctene by $\mathbf{2 a}$ using different solvents and oxidants.

\begin{tabular}{lcccc}
\hline \multirow{2}{*}{ Oxidant } & \multicolumn{4}{c}{$X(\%)$} \\
\cline { 2 - 5 } & Chloroform & Acetonitrile & Ethanol & Toluene \\
\hline$t \mathrm{BuOOH}$ & 78 & 35 & 23 & 16 \\
$\mathrm{H}_{2} \mathrm{O}_{2}$ & 24 & 30 & - & - \\
\hline
\end{tabular}

Reaction conditions: cis-cyclooctene $5.0 \mathrm{mmol}, n$-dodecane $5.0 \mathrm{mmol}$ (internal standard), oxidant $5.0 \mathrm{mmol}$, catalyst $100 \mathrm{mg}$, solvent $10 \mathrm{ml}$, $50{ }^{\circ} \mathrm{C}, 9 \mathrm{~h}$. All selectivities for the epoxide are $\geq 99 \%$. 
and $\mathrm{Cl}^{-}$of PMO-IL. A solution of $\mathrm{H}_{3} \mathrm{PMo}_{12} \mathrm{O}_{40}$ in methanol was gradually added to a suspension of a dispersed in methanol. The mixture was stirred at room temperature and then filtrated. The filtrate was tested using aqueous $\mathrm{AgNO}_{3}$ to verify the presence of $\mathrm{Cl}^{-}$as a consequence of anion exchange. The resulting cloudy precipitate was consistent with this assumption.

For the reference catalyst 2c, the terminal $\mathrm{Si}-\mathrm{OH}$ groups of SBA-15 could also interfere with PMA anions via ion-dipole interactions or hydrogen bonds. However, the supported PMA anions are not very stable under the current test conditions. Karimi et al. [15] reported that an analogous PMA modified SBA-15 catalyst was active for the epoxidation of cyclooctene with $\mathrm{H}_{2} \mathrm{O}_{2}$ as an oxidant. Introducing aminopropyl groups on the SBA-15 surface reportedly further improved the catalytic activity and stability of the supported PMA catalyst. These results suggest that a relatively strong electrostatic interaction between PMA anions and imidazolium cations stabilizes the catalytic active units against leaching during reaction.

The characterization results show that a contains a lower amount of imidazolium cations within the framework than $\mathbf{b}$. So why does the corresponding catalyst 2a stabilize a higher amount of ion-exchanged PMA than $\mathbf{2 b}$ ? Further structural characterization suggests that the difference in the PMA loadings and catalytic properties of $\mathbf{2} \mathbf{a}$ and $\mathbf{2} \mathbf{b}$ may be associated with the different structural features of supports $\mathbf{a}$ and $\mathbf{b}$. Sample a has a higher specific surface area, thus creating more accessible imidazolium cation sites for the electrostatic immobilization of PMA anions. The relatively large pore size of a should provide more space for introducing and stabilizing PMA units and further improve the stability of catalyst $\mathbf{2 a}$.

\section{Conclusions}

Two PMA-functionalized catalysts were obtained through the electrostatic immobilization of PMA on PMO-ILs with different imidazolium contents. Both exhibited good activity and stability in the epoxidation of cyclooctene. The imidazolium cation present in the materials stabilized the PMA active units against leaching into the reaction medium. More efficient heterogeneous catalysts could be achieved by adjusting the surface properties of the PMO-IL support and/or introducing other types of polyoxometalate units into PMO-ILs.

\section{References}

[1] Grigoropoulou G, Clark J H, Elings J A. Green Chem, 2003, 5: 1

[2] Monnier J R. Appl Catal A, 2001, 221: 73

[3] Wu M, Chou L J, Song H L. Chin J Catal (吴妹, 丑凌军, 宋焕玲. 催 化学报), 2013, 34: 789

[4] Wu J H, Jiang P P, Leng Y, Ye Y Y, Qin X J. Chin J Catal (吴江浩, 蒋平 平, 冷炎, 叶媛园, 秦晓洁. 催化学报), 2013, 34: 2236

[5] Ishii Y, Yamawaki K, Ura T, Yamada H, Yoshida T, Ogawa M. J Org Chem, 1988, 53: 3587

[6] Kozhevnikov I V. Chem Rev, 1998, 98: 171

[7] Mizuno N, Yamaguchi K, Kamata K. Coord Chem Rev, 2005, 249: 1944

[8] Dolbecq A, Dumas E, Mayer C R, Mialane P. Chem Rev, 2010, 110: 6009

[9] Long D L, Tsunashima R, Cronin L. Angew Chem Int Ed, 2010, 49: 1736

[10] Kholdeeva O A, Maksimchuk N V, Maksimov G M. Cataly Today, 2010, 157: 107

[11] Kasai J, Nakagawa Y, Uchida S, Yamaguchi K, Mizuno N. Chem Eur J, 2006, 12: 4176

[12] Bordoloi A, Lefebvre F, Halligudi S B. J Catal, 2007, 247: 166

[13] Liu P, Wang H, Feng Z C, Ying P L, Li C.J Catal, 2008, 256: 345

[14] Bordoloi A, Sahoo S, Lefebvre F, Halligudi S B. J Catal, 2008, 259: 232

[15] Karimi Z, Mahjoub A R, Davari Aghdam F. Inorg Chim Acta, 2009, 362: 3725

[16] Liu P, Wang C H, Li C. J Catal, 2009, 262: 159

[17] Estrada A C, Santos I C M S, Simões M M Q, Neves M G P M S, Cavaleiro J A S, Cavaleiro A M V. Appl Catal A, 2011, 392: 28

[18] Karimi Z, Mahjoub A R, Harati S M. Inorg Chim Acta, 2011, 376: 1

[19] Armatas G S, Bilis G, Louloudi M. J Mater Chem, 2011, 21: 2997

[20] Qi W, Wang Y Z, Li W, Wu L X. Chem EurJ, 2010, 16: 1068

[21] Yu X D, Xu L L, Yang X, Guo Y N, Li K X, Hu J L, Li W, Ma F Y, Guo Y H. Appl Surf Sci, 2008, 254: 4444

[22] Zhang R F, Yang C.J Mater Chem, 2008, 18: 2691

[23] Schroden R C, Blanford C F, Melde B J, Johnson B J S, Stein A. Chem Mater, 2001, 13: 1074

[24] Maksimchuk N V, Timofeeva M N, Melgunov M S, Shmakov A N, Chesalov Y A, Dybtsev D N, Fedin V P, Kholdeeva O A.J Catal, 2008,

\section{Graphical Abstract}

Chin. J. Catal., 2014, 35: 532-539 doi: 10.1016/S1872-2067(14)60025-5

\section{Electrostatic immobilization of phosphomolybdic acid on imidazolium-based mesoporous organosilicas for catalytic olefin epoxidation}

Jing Wang, Yongcun Zou, Yu Sun, Maximilian Hemgesberg, Dirk Schaffner, Hongcheng Gao, Xiaojing Song, Wenxiang Zhang, Mingjun Jia*, Werner R. Thiel*

Jilin University, China

Technical University of Kaiserslautern, Germany

Polyoxometalate-based heterogeneous materials were prepared by immobilizing 12-phosphomolybdic acid on imidazolium-based periodic mesoporous organosilicas. These hybrid materials were active and stable heterogeneous catalysts for olefin epoxidation.

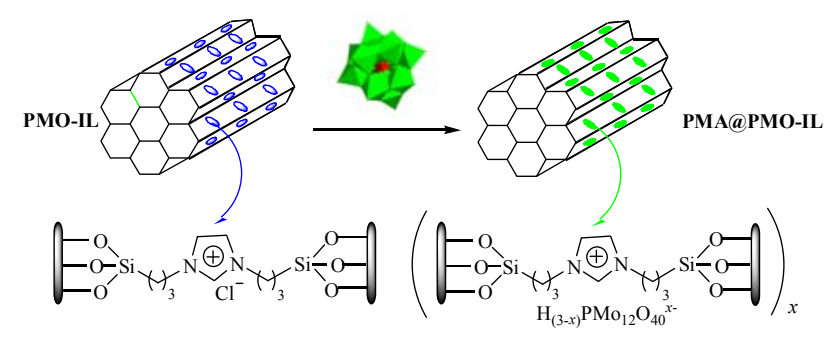


257: 315

[25] Maksimchuk N V, Kovalenko K A, Arzumanov S S, Chesalov Y A, Melgunov M S, Stepanov A G, Fedin V P, Kholdeeva O A. Inorg Chem, 2010, 49: 2920

[26] Maksimchuk N V, Kholdeeva O A, Kovalenko K A, Fedin V P. Isr J Chem, 2010, 50: 1

[27] Du J, Yu J H, Tang J Y, Wang J, Zhang W X, Thiel W R, Jia M J. Eur J Inorg Chem, 2011, 2011: 2361

[28] Zhao H H, Zeng L X, Li Y L, Liu C, Hou B, Wu D, Feng N D, Zheng A M, Xie X L, Su S P, Yu N Y. Microporous Mesoporous Mater, 2013, 172: 67

[29] Karimi B, Elhamifar D, Clark J H, Hunt A J. Chem Eur J, 2010, 16: 8047

[30] Karimi B, Gholinejad M, Khorasani M. Chem Commun, 2012, 48: 8961

[31] Karimi B, Elhamifar D, Clark J H, Hunt A J. Org Biomol Chem, 2011, 9: 7420

[32] Karimi B, Elhamifar D, Yari O, Khorasani M, Vali H, Clark J H, Hunt A J. Chem Eur J, 2012, 18: 13520

[33] Wang L, Shylesh S, Dehe D, Philippi T, Dörr G, Seifert A, Zhou Z,
Hartmann M, Klupp Taylor R N, Jia M J, Ernst S, Thiel W R. ChemCatChem, 2012, 4: 395

[34] Cazin C S J, Veith M, Braunstein P, Bedford R B. Synthesis, 2005, 4: 622

[35] Liu G, Wang Z L, Jia M J, Zou X J, Zhu X M, Zhang W X, Jiang D Z. J Phys Chem B, 2006, 110: 16953

[36] Jin Y, Wang P J, Yin D H, Liu J F, Qiu H Y, Yu N Y. Microporous Mesoporous Mater, 2008, 111: 569

[37] Kim H, Jung J C, Park D R, Lee J, Cho K M, Park S, Lee S H, Song I K. Korean J Chem Eng, 2008, 25: 231

[38] Kim H, Kim P, Lee K Y, Yeom S H, Yi J, Song I K. Catal Today, 2006, 111: 361

[39] Pathan S, Patel A. Dalton Trans, 2011, 40: 348

[40] Essayem N, Holmqvist A, Gayraud P Y, Vedrine J C, Ben Taarit Y. J Catal, 2001, 197: 273

[41] Duncan D C, Chambers R C, Hecht E, Hill C L. J Am Chem Soc, 1995, 117: 681

[42] Thiel W R, Eppinger J. Chem Eur J, 1997, 3: 696

[43] Chandra P, Pandhare S L, Umbarkar S B, Dongare M K, Vanka K. Chem Eur J, 2013, 19: 2030

\title{
咪唑基介孔有机硅材料固载磷钼酸催化剂的制备及烯烃环氧化性能
}

\author{
王 静 ${ }^{\mathrm{a}, \mathrm{b}}$, 邹永存 ${ }^{\mathrm{c}}$, 孙 渝 $^{\mathrm{b}}$, Maximilian Hemgesberg ${ }^{\mathrm{b}}$, Dirk Schaffner ${ }^{\mathrm{b}}$, 高洪成 ${ }^{\mathrm{a}}$, 宋晓静 ${ }^{\mathrm{a}}$, \\ 张文祥 ${ }^{\mathrm{a}}$ ，贾明君 ${ }^{\mathrm{a}, *}$, Werner R. Thiel ${ }^{\mathrm{b}, \#}$ \\ a吉林大学化学学院, 理论化学计算国家重点实验室, 吉林长春130021 \\ b凯泽斯劳滕工业大学化学系, 凯泽斯劳滕 67663, 德国 \\ c吉林大学化学学院, 无机合成与制备化学国家重点实验室, 吉林长春130012
}

摘要：以含有咪唑阳离子的周期性介孔有机硅(PMO-ILs) 材料为载体, 制备了一类固载化磷钿酸(PMA)多相催化材料 (PMA@PMO-ILs), 并采用 $\mathrm{N}_{2}$ 吸附-脱附实验、X射线衍射、原子吸收光谱、差热-热重分析、红外光谱、紫外光谱及固体核磁共振 技术研究了材料的结构及物理化学性质. 结果表明, 磷钿酸通过静电相互作用被成功固载到PMO-ILs载体表面和孔道中, 且在制 备过程中磷锄酸及载体基本结构均未发生变化. 反应结果表明, PMA@PMO-ILs材料在以叔丁基过氧化氢为氧化剂的环辛烯环 氧化反应中表现出一定的催化活性和很高的选择性. 中断实验结果表明, 催化剂的主要活性中心在反应过程中未发生明显流失, 且催化剂经多次循环使用后活性及选择性基本保持不变. PMO-ILs中大量的咪唑阳离子能有效稳定磷钿酸阴离子, 使该催化材料 表现出良好的稳定性.

关键词: 多金属氧酸盐; 介孔有机硅; 咪唑阳离子; 静电相互作用; 环氧化; 多相催化

收稿日期: 2013-11-14. 接受日期: 2014-01-02. 出版日期: 2014-04-20.

*通讯联系人. 电话: (0431)85155390; 传真: (0431)88499140; 电子信箱: jiamj@jlu.edu.cn

通讯联系人. 电话: +49-631-2052752; 传真: +49-631-2054676; 电子信箱: thiel@chemie.uni-kl.de

基金来源: 中国国家留学基金管理委员会; 国家自然科学基金(21173100).

本文的英文电子版由Elsevier出版社在ScienceDirect上出版(http://www.sciencedirect.com/science/journal/18722067). 